\title{
Design and implementation of a quasi-resonant flyback switching power supply
}

\author{
ZhiJun Guo, a , YongJun Dai ${ }^{2, b}$ \\ ${ }^{1}$ Zhejiang University of Water Resources and Electric Power, Hangzhou,Zhejiang,China 310018 \\ ${ }^{2}$ Zhejiang JEC new Eenergy Technology Co., Ltd \\ a865418339@qq.com, bdaiyj@jec.com.cn
}

Keywords: Quasi-resonant converter, DC-DC converter,Soft-switching technology.

Abstract. According to the new energy electric vehicle DC-DC conversion needs to adopt a zero-voltage quasi-resonant flyback converter topology based DC conversion program that will convert DC72V power to low voltage DC12V vehicle auxiliary power supply, simple circuit structure, components used, low cost energy efficient. To improve and optimize the performance of electric vehicles powered structure has important significance.

\section{Introduction}

In this paper, the current low-voltage electrical equipment and power supply systems electric car does not match the problem with the status quo and the development of electric vehicles DC $12 \mathrm{~V}$ power supply system electrical equipment, electric vehicle proposed quasi-resonant flyback DC-DC converter modules Research Program. The program is based on the quality of the current automotive DC-DC converter module light, small size, high efficiency, low interference, and safety and reliability requirements of the development proposed by ${ }^{[1]}$, it has some innovative and practical. First, the circuit structure using a flyback topologies, small electromagnetic interference, simple circuit structure, the use of fewer components, help reduce production costs; Second, the research program uses a quasi-resonant soft-switching technology, jump cycle control strategy and synchronous rectification technology, its high conversion efficiency, up to $90 \%$, small standby loss, less than $1 \mathrm{~W}$, is conducive to integration and "green" energy converter to achieve the body.

\section{Quasi-resonant flyback converter topology analysis}

Quasi-resonant flyback converter topology shown in Figure 1, where, Lp is the transformer primary inductance, Ls transformer secondary inductance, Cs resonant capacitor. As can be seen from Figure 1, the quasi-resonant flyback converter flyback converter in the original basis on the main switch at both ends of a capacitor in parallel, it is easy to implement. The use of quasi-resonant flyback converter primary inductor and resonant capacitor resonant transformer at the bottom of the opening of the switch, the switch is opened to reduce the loss due to the parasitic capacitance of the switch is relatively small, so the switch in parallel across a capacitor. It works roughly as follows: the switch is turned on, the primary winding energy storage capacitor to the load provided by the secondary energy; switch off, the buffer circuit, the release of stored energy transformer; energy release is completed, the capacitance Cs and primary inductance Lp occur resonates through the secondary diode reverse recovery process; and resonant opened.

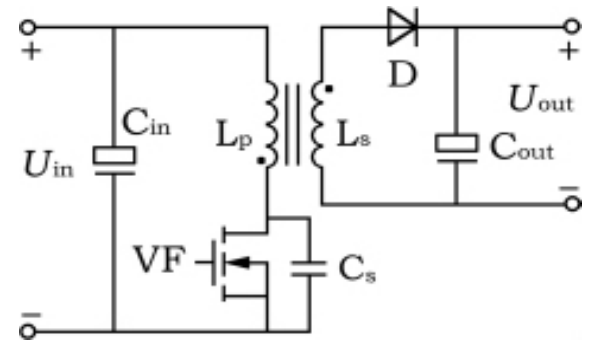

Figure 1 Circuit topology 


\section{EV 150 W quasi-resonant flyback DC-DC converter circuit design}

According to the current power needs of a variety of electric vehicles $12 \mathrm{~V}$ electrical equipment, designed a $150 \mathrm{~W}$ quasi-resonant flyback DC-DC converter circuit, the main high voltage electric car battery is reduced, to give electric car speakers, front lamps, air conditioning, audio, instruments, accelerators $12 \mathrm{~V}$ power supply. The principle is shown in Figure 2.

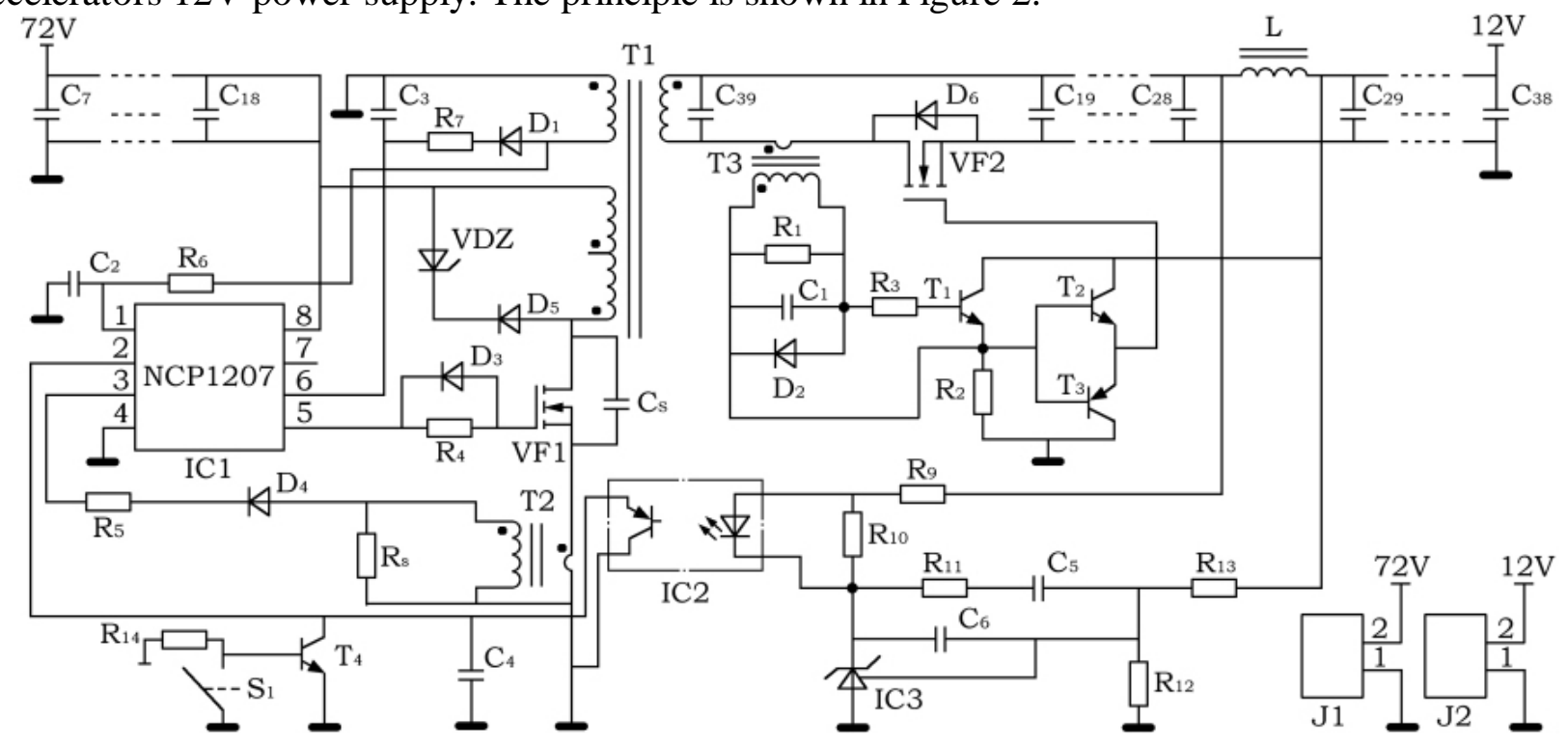

Figure 2 quasi-resonant flyback DC-DC converter circuit schematics

In this design, the control circuit uses ONSemi company's control chip NCP1207, it uses skip mode control, which greatly optimizes the quasi-resonant flyback converter switching frequency dependent on the load and input voltage, which can reduce light load or the purpose of the no-load losses; NCP1207 integrates a current-mode regulator and a demagnetization detector to ensure that the circuit under any conditions in the free running quasi-resonant mode of operation... Chip critical control mode and zero-voltage mode so that in the case of input, load changes, it is possible to reduce losses and improve efficiency.

Power transformer parameters are as follows: Minimum DC input voltage of $60 \mathrm{~V}$, the output voltage of $12 \mathrm{~V}$; the average output current $12.5 \mathrm{~A}$, the output power of $150 \mathrm{~W}$, power supply topologies: quasi-resonant discontinuous flyback mode, the switching frequency of $61.2 \mathrm{kHz} ; 90 \%$ efficiency, maximum the duty cycle of 0.5 .

Peak of primary side current

$$
I_{\mathrm{P}}=\frac{2 P_{\text {out }}}{U_{\text {immin }} D_{\text {max }} \eta}=\frac{2 \times 150}{60 \times 0.5 \times 0.9}=11.11 \mathrm{~A}
$$

Valid values for primary side current

$$
I_{\mathrm{Pms}}=I_{\mathrm{P}} \sqrt{\frac{D_{\max }}{3}}=11.11 \times \sqrt{\frac{0.5}{3}}=4.4 \mathrm{~A}
$$

Inductance value of a side

$$
L_{\mathrm{P}}=\frac{U_{\mathrm{immin}} t_{\text {ammix }}}{I_{\mathrm{P}}}=\frac{60 \times 8.17 \times 10^{6}}{11.11}=44 \mu \mathrm{H}
$$

A winding circle number for

$$
N_{\mathrm{P}}=\frac{U_{\text {inmin }} t_{\text {onmax }} \times 100}{\Delta B_{\mathrm{m}} A_{\mathrm{e}}}=\frac{60 \times 8.17 \times 100}{1667 \times 1.96}=15
$$

Ferrite core material selection, select the maximum saturation flux density of $0.3 \mathrm{~T}$ (3000Gs), in order to prevent core saturation, the maximum flux density swing try to get a little low, this design value of $1667 \mathrm{Gs}$. According to the inverter output power and switching frequency, select the core 
model PQ35 / 35, while the core effective cross-sectional volume of $1.96 \mathrm{~cm} 2$, core skeleton select PC40.

The secondary winding turns to

$$
N_{\mathrm{S}}=\frac{N_{\mathrm{P}}\left(U_{\text {out }}+U_{\mathrm{F}}\right)}{U_{\mathrm{R}}}=\frac{15 \times 12}{60}=3
$$

Secondary voltage 12V, 3 turns, RMS 20 A, need to cut wires and plot $8 \mathrm{~mm}^{2}$, each $2.67 \mathrm{~mm}^{2}, 0.05$ $\mathrm{mm}$ with a 3-layer copper foil, add each of the winding insulation layer 12, a thickness of $0.6 \mathrm{~mm}, 3$ the total thickness of the secondary winding is $1.8 \mathrm{~mm}$

\section{Quasi-resonant capacitor design}

$$
\begin{aligned}
& C_{\mathrm{s}}=\frac{T^{2}{ }_{\mathrm{LC}}}{4 \pi^{2} L_{\mathrm{P}}}=\frac{\left(4 \times 10^{-6}\right)^{2}}{4 \times 3.14^{2} \times 44}=9 \mathrm{nF} \\
& \mathrm{C}_{\mathrm{s}} \text { Optional } 103 / 1 \mathrm{kV} \text { film capacitors }
\end{aligned}
$$

\section{Power switch choices}

In order to improve the efficiency of the converter, choose the relatively small turn-on loss of the MOSFET as the design of the power switch. Since the switch voltage comprises a voltage supply portion, part of the reset voltage, spike voltage part ${ }^{[2]}, 72 \mathrm{~V}$ battery power supply level of maximum 90 $\mathrm{V}$, taking the reset voltage $60 \mathrm{~V}$, the peak voltage of 30 to $60 \mathrm{~V}$, considering $30 \sim$ safety margin of 50 $\mathrm{V}$, so choose $250 \sim 300 \mathrm{~V}$ breakdown voltage MOSFET; switch rated peak current transformer selection generally take 3 to 4 times to swallow, since $\mathrm{I}_{\mathrm{p}}$ is $11.11 \mathrm{a}$, so in the design of the switch rated 42A current selection. Through the above two parties and selection, chose IXTQ42N25P MOSFET switch tube $\mathrm{U}_{\mathrm{DSS}}=250 \mathrm{~V}, \mathrm{I}_{\mathrm{D}}=42 \mathrm{~A}, \mathrm{R}_{\mathrm{Dson}}=84 \mathrm{~m} \Omega$, TO-247DS package.

\section{Synchronous rectifier output circuit design}

In order to further improve the overall efficiency of the converter to reduce output circuit losses. The design elements constitute a use classification self-driven synchronous rectifier output circuit. Improving efficiency, reducing costs ${ }^{[3]}$ The circuit shown in Figure 3.

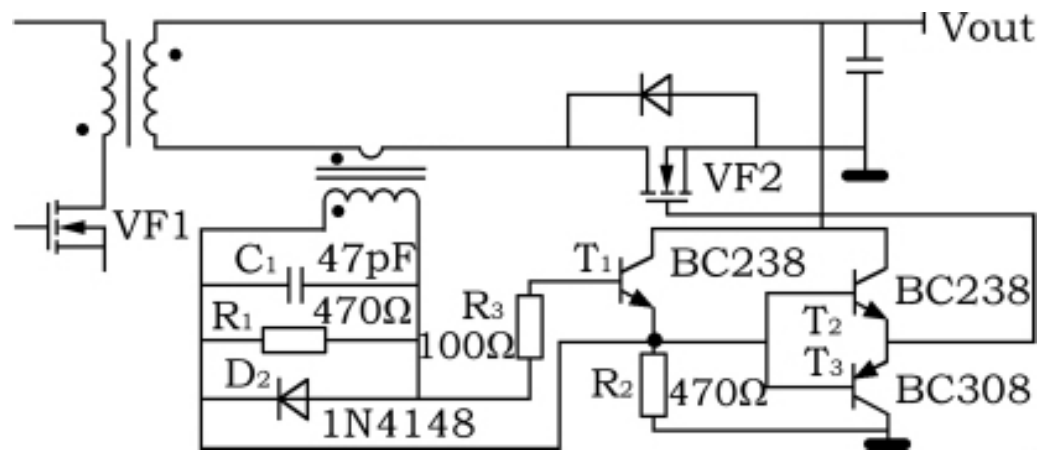

Figure 3 Self-driven synchronous rectifier circuit

Self-driven synchronous rectifier circuit works: reverse diode conduction through the synchronous rectifier VF2 flow through the output current, while the secondary side of the current transformer to obtain induced current flows into the resistor $R_{1}$, to produce $U=I^{2} R$ on $R_{1}$ induced voltage. when this voltage reaches and exceeds the transistor emitter junction when forward voltage, $T_{1}$ is turned on, and the drive is turned on $\mathrm{T}_{2}, \mathrm{~T}_{2}$ pulled emitter voltage to the output voltage to drive synchronous rectifier MOSFET is turned on the output current is reduced to when the turn-on threshold T1 or less, off $\mathrm{T}_{1} ; \mathrm{T}_{2}$ of the base are not paranoid current, at the same time due to the $T_{2}, T_{3}$ has a base grounding resistors $R_{2}$, can be $T_{2}, T_{3}$ low base voltage. Resistor $R_{2}$ can be made synchronous rectifier gate charge through $\mathrm{T}_{3}$ conducting rapid discharge, in order to achieve timely and synchronous rectifier MOSFET is turned off. 


\section{Test results and analysis}

The conversion efficiency of the test, the input voltage is DC $60 \mathrm{~V}, 72 \mathrm{~V}$, at $90 \mathrm{~V}$, respectively, two 150W DC-DC converter efficiency comparison test prototype, respectively, to draw a graph comparing the efficiency. One of which is UC3842 control chip PWM control mode to achieve 150W / $12 \mathrm{~V}$ output converter; the other is to use the NCP1207 control chip $150 \mathrm{~W} / 12 \mathrm{~V}$ output of the quasi-resonant converter control methods to achieve. 4, the flyback converter NCP1207 than UC3842 flyback converter efficiency by approximately $4 \%-5 \%$ in FIG. Since the main loss flyback DC-DC converter transformer leakage inductance and switch off additional losses due process caused by the leakage inductance of the transformer, if the loss is basically eliminated, the efficiency can be increased by $6 \%$ or more. Thus, the quasi-resonant add intelligent synchronous rectifier combinations you can get more than $90 \%$ of the DC-DC conversion efficiency.

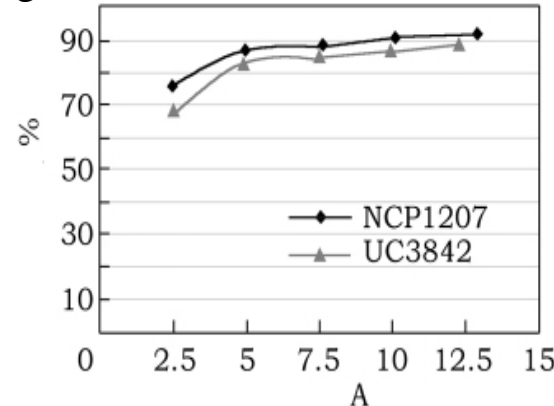

(a) $60 \mathrm{~V}$

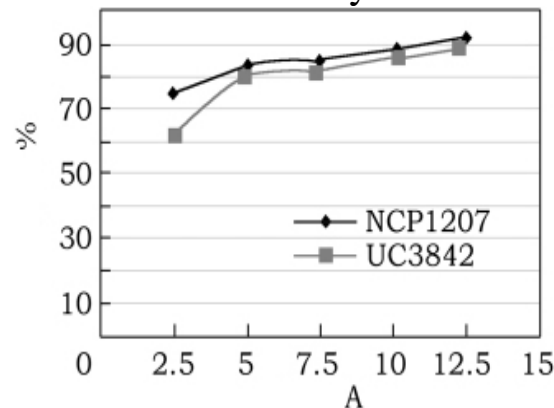

(b) $72 \mathrm{~V}$

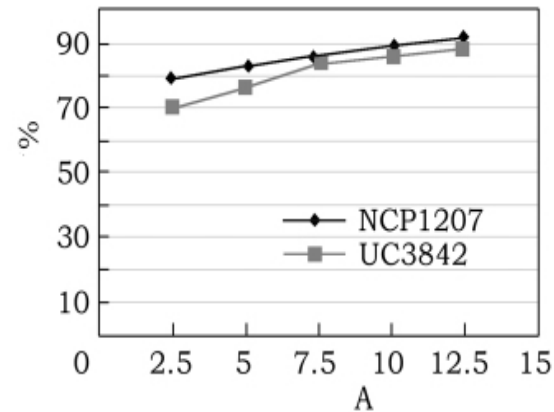

(c) $90 \mathrm{~V}$

Figure 4 efficiency curve

\section{Conclusion}

In summary, the design of the quasi-resonant flyback DC-DC converter with a simple circuit structure, small electromagnetic interference and advanced soft switch and synchronous rectification technology to achieve high efficiency, reduce production costs and purposes, as an electric $12 \mathrm{~V}$ vehicle power supply system spare conversion equipment, has a strong practical and superiority. The research program improvements and breakthroughs based on the current vehicle DC-DC converter on development; the implementation of the program, to a certain extent, can compensate for the lack of electric vehicle power supply system, improve the electric car's energy supply structure, optimizing the performance of electric vehicles, to promote the development of electric vehicles has great significance.

\section{Acknowledgements}

This work was financially supported by the National High-Tech R\&D Program（863 Program）, project number 2014 AA052005.

\section{References}

[1] Liu FengHua: Chen Lei Research About Quasi-resonant Converter Module for EV. Auto Electric 2013 Section 3 16-19

[2] Xia Liang: Design of electric vehicle drive switching power supply Used to Tongji University Master Thesis, 2008.

[3] ChenYongzhen: Switching power supply into the era of high-efficiency power conversion power in the world, 2007 (2): 6-7,23. 